\title{
Practice Organization Characteristics Related to Job Satis- faction Among General Practitioners in 11 Countries
}

Christine Cobidon, $M D, P b D^{1}$

Pascal Wild, $P b D^{1,2}$

Nicolas Senn, MD, $P b D^{1}$

${ }^{1}$ Center for Primary Care and Public Health (Unisanté), University of Lausanne, Lausanne, Switzerland

${ }^{2}$ INRS - National Research and Safety Institute, Vandoeuvre les Nancy, France

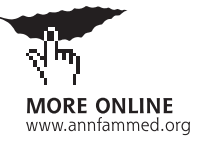

Conflicts of interest: authors report none.

\section{CORRESPONDING AUTHOR}

Christine Cohidon, MD, PhD

Center for Primary Care and Public Health

(Unisanté)

Rue du Bugnon 44

$\mathrm{CH}-1011$ Lausanne, Switzerland

christine.cohidon@hospvd.ch

\begin{abstract}
PURPOSE The consequences of job dissatisfaction among general practitioners (GPs) are well known; both GPs and policy makers should be interested in a better understanding of its determinants. This study aimed to investigate whether the organizational and functional features of GPs' practices were associated with job dissatisfaction in 11 countries.
\end{abstract}

METHODS We conducted a secondary analysis of the 2015 Commonwealth Fund International Health Policy Survey of Primary Care Physicians, $(n=12,049)$. Job dissatisfaction was measured on a 4-point Likert scale using the question: "How satisfied are you regarding your practicing of medicine?" Numerous practice organization characteristics were considered using a multilevel, mixed-effects, ordered logistic regression analysis.

RESULTS Prevalence of dissatisfaction at work varied from $8.1 \%$ in Norway to $37.4 \%$ in Germany. Dissatisfaction was higher among middle-aged (aged 45-54 years) GPs (adjusted odds ratio (AOR) $=1.32$ [1.17-1.49]), those practicing in urban areas (AOR $=1.12$ [1.03-1.22]), and those working alone. It was associated with a high weekly workloads (AOR $=1.26$ [1.12-1.42] if $>50$ hours), heavy administrative burdens ( $\mathrm{OR}=1.55$ [1.37-1.73]), long delays in hospital discharge notices (AOR $=1.82$ [1.52-2.19] if $>1$ month), and limited possibilities of offering same-day appointments (AOR $=1.83$ [1.34-2.50]). Using electronic health records $(\mathrm{OR}=0.82$ [0.68-0.98]) and having an in-practice case manager $(A O R=0.84$ [0.75-0.95]) were associated with lower dissatisfaction.

CONCLUSIONS Heavy workloads are clearly associated with job dissatisfaction among GPs. Organizational changes such as group practices, employing case managers, and using electronic health records could potentially reduce this burden. Workloads could also be relieved by diversifying GPs' activities. All health care providers should strive to improve the circulation of information.

Ann Fam Med 2019;17:510-517. https://doi.org/10.1370/afm.2449.

\section{INTRODUCTION}

$\square$ issatisfaction at work and related job stress are recognized as major issues in high-income countries in all sectors. Health care has been reported to be one of the most exposed sectors, partly due to significant emotional commitments and heavy workloads. ${ }^{1}$ Many recent studies of primary care have described job dissatisfaction and job stress among general practitioners/family physicians (GPs) ${ }_{1}^{2-14}$ and 3 consequences of this exposure have been reported: first, deleterious effects on individual mental health, such as burnout and depressive syndromes ${ }^{2,3,11,15,16}$; second, a crisis in the recruitment and retention of $\mathrm{GPs}^{5,17-21}$; and third, repercussions on the quality of patient care..$^{22-24}$

If it is critical to know the potential repercussions of job dissatisfaction on GPs, it also seems necessary to understand the determinants of that dissatisfaction. Heavy workloads are commonly reported to be deleterious factors, whereas GPs generally value the organizational freedom and diversity of their work highly. ${ }^{25-30}$ Regarding health care systems, many countries have recently made or experimented with sig- 
nificant changes to address the challenges of aging populations and concerns about cost containment. The strengthening of primary care, combined with greater regulation, is a frequently chosen option. In this context, and in addition to potential shortage in many countries, GPs are under pressure, and their job satisfaction seems to be more threatened. ${ }^{31,32}$ Few previous studies have investigated the potential impacts of recent changes in the organization of PC practices on GPs' job satisfaction, and those that did generally looked at 1 country ${ }^{4,6,12,33-37}$ and often examined but few factors simultaneously.

This study's objective was to use international comparisons to explore the structural and organizational factors associated with GPs' dissatisfaction at work. The findings may be useful for both GPs and health policy makers.

\section{METHODS}

\section{Commonwealth Fund International Surveys}

The data came from the last Commonwealth Fund International Health Policy Survey of Primary Care Physicians conducted in 2015. ${ }^{38}$ Since 2006, the Commonwealth Fund has conducted international surveys of nationally representative random samples of PC physicians regarding their practices' preparedness to manage the care of patients with complex needs (both children and adults), offer patient access, communicate with other specialty and community-based clinicians, and use health information technology. The survey also covers their views about their national health care system and satisfaction with aspects of their practice..$^{39}$ Eleven countries participated in the 2015 edition: Australia, Canada, France, Germany, the Netherlands, New Zealand, Norway, Sweden, Switzerland, the United Kingdom, and the United States.

\section{Population and Data Collection}

The study protocol has been detailed elsewhere ${ }^{38,39}$; here we present its main characteristics. Samples of practicing PC physicians were drawn from government or private lists in each country. The different medical specialties of the PC physicians included were specific to each country. General practitioners and family physicians were included in all countries, as well as internists and pediatricians in Germany, Switzerland, and the United States. Survey data-collection modes were tailored to each country's best practices for communicating with physicians. Postal surveys were conducted in Germany, the Netherlands, and Norway. For Australia and New Zealand, physicians were recruited by phone and responded to surveys online or by post. Online and postal surveys were conducted in Canada, Sweden, and the United States, whereas phone and online surveys were conducted in the United Kingdom and Switzerland. Final sample sizes ranged from 503 to 2,905. Data were weighted, based on known population parameters for each country to ensure that they were representative of the primary care physician population.

\section{Data}

A common questionnaire was reviewed by experts in each country, adjusted for country-specific wording, and translated as needed to ensure comparability across countries. ${ }^{40}$

One question explored job satisfaction: "Overall, how satisfied are you with practicing medicine?" and was measured using a 4-point Likert scale ("Very satisfied $_{i}$ Satisfied, Somewhat dissatisfied $_{i}$ Very dissatisfied"). Numerous further questions investigated the practices' organizational characteristics. We classified these questions into 4 domains:

(1) General organization and workload indicators, including the number of GPs in the practice, weekly workloads, percentages of same- or next-day appointments, home visits, consultation lengths, and percentage of administrative tasks.

(2) Coordination factors, including working with a case manager, inter-consultation contacts with patients, delays regarding hospital discharge, and care coordination with hospitals and social care institutions.

(3) Factors related to quality of care indicators, including information on clinical outcomes and preventive targets, patient satisfaction surveys, information regarding patient hospitalizations and the use of emergency departments, performance targets, and comparisons with other GPs.

(4) Use of information technology, including the use of electronic health records and prescribing alerts.

GPs' sociodemographic data such as sex, age, and rural/urban practice areas (self-reported) completed the set of independent variables.

\section{Statistical Analysis}

The Commonwealth Fund provided country-specific sampling weights which account for the potential overrepresentation of GPs in relation to some factors and can thus explain differential nonresponse along known geographic and demographic parameters. ${ }^{38}$

First, we produced descriptive statistics characterizing the prevalence of satisfaction at work and the organizational features seen in the different countries. Then we carried out 2-step multilevel (country/practice), weighted, mixed-effects, ordered logistic regressions, with the country as the random factor. In step 1, we considered associations between the dependent 
variable, job dissatisfaction and practice characteristics one at a time (including adjustment for sex, age, and location). We retained the variables associated at a $P$ value of 0.2 or less. Next, we performed a manual, backward, stepwise selection (removal of the least significant variable at each step) to obtain a final model.

In step 2, we tested the interactions between each independent variable and the country. Because we observed statistically significant interactions for most of them, we finally conducted stratified analyses for each country, using a standard, weighted, ordered logistic regression including all independent variables. All statistical analyses were performed using Stata Software (StataCorp LLC).

\section{RESULTS}

Table 1 presents the main sample characteristics according to country. The complete description of the sample is available in Supplemental Table 1, available at http://www.AnnFamMed.org/content/17/6/510/suppl/ DC1/. The questionnaire was completed by 12,049 GPs (ranging from 502 in France to 2,905 in Sweden). The proportion of women varied from $30 \%$ in Switzerland to $50 \%$ in New Zealand; the proportion of GPs aged under 45 years was $14 \%$ in Germany but $44 \%$ in Australia. The organizational and functional features vary from one country to another. Examples include the composition of group practices, consultation durations, working with a case manager, and the use of quality indicators (Table 2, and Supplemental Table 1). The prevalence of dissatisfaction at work (combined percentage of "Somewhat dissatisfied" and "Very dissatisfied" answers) varied from $8.1 \%$ in Norway to $37.4 \%$ in Germany. (Table 2).

\section{GP Job Dissatisfaction and Associated Factors, Global Model}

Job dissatisfaction was higher among middle-aged GPs (odds ratio $(\mathrm{OR})=1.32[1.17-1.49]$ ) aged 45-54 years and for those aged $55-64$ years $(\mathrm{OR}=1.25[1.10-1.42])$. In contrast, it was lower among the older GPs in our sample $(\mathrm{OR}=0.67$ [0.52-0.88], probably reflecting a selection effect in which dissatisfied GPs retired earlier, and those practicing in urban areas $(\mathrm{OR}=1.13[1.03$ 1.23]). Job dissatisfaction was also lower in practices including more than 2 GPs. Dissatisfaction increased with the weekly workload $(\mathrm{OR}=1.26[1.12-1.42]$ if $\geq 50$ hours per week), the percentage of time dedicated to administrative tasks $(\mathrm{OR}=1.55(1.37-1.73)$ (Table 3$)$ if $>20 \%$ ) and with a lower possibility of offering sameday appointments $(\mathrm{OR}=1.83$ [1.34-2.50] when $<20 \%)$. In contrast, GPs' dissatisfaction was lower when they provided home care visits $(\mathrm{OR}=0.89$ [0.83-0.96]), when involved in coordinated care with hospitals $(\mathrm{OR}=0.84$ [0.76-0.93]) and when they worked with a case manager within the practice $(\mathrm{OR}=0.84$ [0.75-0.95]). Long delays in receiving discharge information were associated with job dissatisfaction, with a significant gradient effect. Finally, regarding information technology, GP dissatisfaction was lower if they used electronic health records $(\mathrm{OR}=0.82[0.68-0.98])$ but higher if they only used electronic alerts about drug prescriptions occasionally $(\mathrm{OR}=1.43[1.17-1.75])($ Table 3$)$

Table 1. Characteristics of Respondents and GP Satisfaction in the 11 Countries

\begin{tabular}{|c|c|c|c|c|c|c|c|c|c|c|c|}
\hline & $\begin{array}{l}\text { AU } \\
747\end{array}$ & $\begin{array}{c}\text { CA } \\
2,284\end{array}$ & $\begin{array}{c}\text { FR } \\
502\end{array}$ & $\begin{array}{c}\text { DE } \\
559\end{array}$ & $\begin{array}{l}\text { NL } \\
618\end{array}$ & $\begin{array}{c}\mathrm{NZ} \\
503\end{array}$ & $\begin{array}{l}\text { NO } \\
864\end{array}$ & $\begin{array}{c}\text { SE } \\
2,905\end{array}$ & $\begin{array}{c}\mathrm{CH} \\
1,065\end{array}$ & $\begin{array}{c}\text { UK } \\
1,001\end{array}$ & $\begin{array}{c}\text { US } \\
1,001\end{array}$ \\
\hline Sex, female, \% & 37.0 & 43.8 & 35.0 & 44.3 & 45.3 & 45.0 & 40.0 & 51.5 & 32.9 & 49.1 & 39.9 \\
\hline \multicolumn{12}{|l|}{ Age, y, \% } \\
\hline$<35$ & 11.3 & 9.5 & 7.8 & 1.0 & 4.5 & 9.0 & 13.1 & 9.1 & 0.8 & 13.8 & 5.5 \\
\hline $35-44$ & 28.8 & 22.1 & 15.8 & 35.7 & 28.1 & 29.0 & 31.7 & 26.6 & 18.1 & 30.9 & 20.3 \\
\hline $45-54$ & 32.1 & 27.5 & 28.1 & 27.6 & 31.3 & 40.0 & 22.0 & 24.3 & 31.3 & 30.0 & 30.1 \\
\hline $55-64$ & 17.3 & 26.3 & 39.0 & 28.6 & 33.3 & 18.0 & 27.0 & 28.1 & 36.4 & 19.2 & 28.8 \\
\hline$\geq 65$ & 10.5 & 14.5 & 9.3 & 7.1 & 2.7 & 4.0 & 6.2 & 11.8 & 13.5 & 6.2 & 16.1 \\
\hline Urban area, \% & 71.8 & 66.7 & 70.4 & 52.9 & 46.6 & 69.7 & 37.7 & 52.4 & 51.5 & 68.0 & 72.1 \\
\hline GPS FTE in the practice (median) & 5 & 4 & 1 & 1 & 2 & 4 & 4 & 4 & 2 & 5 & 3 \\
\hline \multicolumn{12}{|l|}{ GP Satisfaction at work, \% } \\
\hline Very satisfied & 35.1 & 29.3 & 9.2 & 11.5 & 16.6 & 33.0 & 39.5 & 26.9 & 27.6 & 13.6 & 19.0 \\
\hline Satisfied & 53.0 & 55.0 & 57.1 & 52.1 & 67.8 & 53.5 & 52.4 & 48.5 & 58.7 & 53.2 & 46.5 \\
\hline Somewhat dissatisfied & 10.8 & 14.5 & 24.0 & 30.5 & 14.6 & 12.1 & 7.5 & 20.5 & 11.7 & 29.0 & 28.6 \\
\hline Very dissatisfied & 1.1 & 1.1 & 9.8 & 6.9 & 1.0 & 1.4 & 0.6 & 4.1 & 2.0 & 5.9 & 5.9 \\
\hline
\end{tabular}


Table 2. Practices' Main Characteristics in the 11 Countries

\begin{tabular}{|c|c|c|c|c|c|c|c|c|c|c|c|}
\hline $\begin{array}{l}\text { Practice organizational } \varepsilon \\
\text { functioning features }\end{array}$ & $\begin{array}{c}\mathrm{AU} \\
747\end{array}$ & $\begin{array}{c}\text { CA } \\
2,284\end{array}$ & $\begin{array}{c}\text { FR } \\
502\end{array}$ & $\begin{array}{l}\text { DE } \\
559\end{array}$ & $\begin{array}{l}\text { NL } \\
618\end{array}$ & $\begin{array}{l}N Z \\
503\end{array}$ & $\begin{array}{l}\text { NO } \\
864\end{array}$ & $\begin{array}{c}\text { SE } \\
2,905\end{array}$ & $\begin{array}{c}\mathrm{CH} \\
1,065\end{array}$ & $\begin{array}{l}\text { UK } \\
1,001\end{array}$ & $\begin{array}{l}\text { US } \\
1,001\end{array}$ \\
\hline Consultation duration (median, min) & 15 & 15 & 20 & 10 & 10 & 15 & 20 & 20 & 20 & 10 & 15 \\
\hline Weekly workload (median, hours) & 40 & 40 & 50 & 50 & 45 & 36 & 40 & 40 & 48 & 44 & 45 \\
\hline $\begin{array}{l}\text { Part dedicated to admin task (\% total, } \\
\text { median) }\end{array}$ & 10 & 15 & 15 & 20 & 20 & 20 & 20 & 22 & 20 & 20 & 10 \\
\hline Frequently & 25.1 & 19.5 & 56.1 & 57.1 & 88.3 & 20.6 & 20.3 & 24.7 & 42.8 & 84.0 & 6.0 \\
\hline Occasionally & 59.6 & 49.4 & 34.2 & 30.0 & 11.7 & 74.8 & 77.8 & 70.1 & 45.4 & 15.1 & 28.6 \\
\hline No & 25.1 & 31.1 & 9.7 & 13.0 & 0.0 & 4.6 & 2.0 & 5.2 & 11.8 & 0.8 & 65.4 \\
\hline \multicolumn{12}{|l|}{ Working with case manager, \% } \\
\hline In practice & 75.4 & 42.9 & 12.9 & 20.6 & 83.0 & 83.0 & 31.8 & 75.8 & 8.4 & 87.4 & 43.9 \\
\hline External & 6.2 & 21.5 & 83.3 & 6.8 & 14.9 & 7.4 & 33.9 & 9.8 & 52.2 & 8.3 & 22.8 \\
\hline Use of EHR, \% & 92.4 & 72.9 & 75.6 & 85.5 & 99.3 & 99.8 & 99.5 & 99.3 & 54.3 & 98.4 & 84.5 \\
\hline
\end{tabular}

\section{Job Dissatisfaction and Associated Factors in Each Country}

When we applied the same full model to each country individually and compared the results, we distinguished 2 kinds of results. Most independent variables were associated with job dissatisfaction in the same direction. The characteristics most often associated with job dissatisfaction were: administrative overloads, weekly workloads, delays in receiving discharge information, and intermediate-to-older age classes (aged 45-65 years). For a few independent variables however, ie, GP sex, consultation duration, practice size, and the use of electronic drug alerts, the direction of association varied according to the country (see Supplemental Appendix 2 at http://www.AnnFamMed.org/ content/17/6/510/supp1/DC1/ for complete results).

\section{DISCUSSION}

The present study of job dissatisfaction among GPs in 11 countries first showed high variations in its prevalence, with high prevalence in middle-aged GPs. Second, our analysis reported associations between high job dissatisfaction and several job characteristics such as overall workload and long delays in receiving discharge information from hospitals. Job dissatisfaction was generally lower, however, among GPs working in group practices alongside a case manager and those carrying out home visits, involved in care coordination with hospitals, and using electronic health records. Finally, other results pertaining to GPs' sex, consultation durations, practice size, and the use of electronic drug alerts were less consistent between countries.
The literature has already described the burden of workload, especially the time dedicated to administrative tasks, as contributing to job dissatisfaction ${ }^{26,41,42}$ and it is one of the strongest associations we revealed in this study. One surprise was the association between job dissatisfaction and difficulties in offering same-day appointments. We could try to explain this by hypothesizing that this variable reveals the time pressures which GPs are under, as well as the latitude they have to organize their activities throughout the day. These 2 concepts are key elements on job stress, in reference to the Karasek model, where the imbalance between quantitative (and qualitative) job demand and job control (or latitude) is seen as a source of distress. ${ }^{43}$

We reported lower dissatisfaction among GPs involved in different activities, both in their practices and outside, such as home visits and care coordination with hospitals. The idea that diversifying activities could be a source of well-being for GPs is an emerging one in the literature ${ }^{27,44}$ and it could be an interesting option to improve GP satisfaction. Observation about practice sizes were also interesting in the current context of a transformation of general medicine. There are fewer and fewer practices with just 1 physician, as combining resources and improving continuity and coordination of care encourages GPs to work in group practices. Our results indicated that this was potentially also beneficial for their well-being and satisfaction at work. Likewise, PC practice evolves, working with a case manager within the practice appears to be a positive move toward job satisfaction. Other studies have already reported the positive effects of case managers on team climate but GP's acceptation of task delegation was more nuanced. ${ }^{28}$ 
In accordance with the literature, physicians working in rural areas were more satisfied with their job than those in urban areas. ${ }^{26}$ General practitioners' activities are probably quite different in rural and urban settings and, in general, rural GPs carry out a more comprehensive list of activities, leading to a more complete patient type of management, which is perhaps more gratifying in terms of work satisfaction. Also, relationships with patients are perhaps stronger in rural areas, generating lessdemanding patients. The present study also investigated the impact of quality assessments on the GP practices, ie, performance comparisons, targets to reach, or patient-satisfaction surveys. We initially hypothesized that exposure to these factors might generate job-related discontent, but no statistical associations were found in our results. Along these lines, Allen and colleagues recently reported that a UK pay-for-performance scheme had had no significant effect on GPs' job satisfaction. ${ }^{35}$

We found that some of our results were inconsistent across countries. This was the case, for instance, for associations pertaining to GPs' sex, group practices, and consultation durations. Other variables pertaining to $\mathrm{PC}$ organization, which would allow us to interpret these results fully, are missing. This study should be followed up by more specific quantitative and qualitative research.

\section{Strengths and Limitations}

There are some limitations to this study. Differences in GP participation rates (from 19\% to $47 \%$ ) and nonresponses might be linked to GPs' opinions and practices. The data were weighted to account for differential nonresponse, however, regarding known geographic and demographic parameters, which could have limited this selection bias. ${ }^{38,45}$ Some key variables, such as methods of remuneration, are missing. Data were self-reported, and they may therefore have been exposed to declaration biases for different reasons (eg, memory and influence of other parameters). Most of the independent variables, however, were factual, which limits the circular phenomenon of data (when independent and dependent variables are self-
Table 3. Associations Between Work Dissatisfaction and Physician and Practice Characteristics

\begin{tabular}{|c|c|c|c|}
\hline $\begin{array}{l}\text { Physician } \\
\text { Characteristics }\end{array}$ & No. & $\begin{array}{c}\text { Single } \\
\text { Independent } \\
\text { Variables } \\
\text { OR (CI 95\%) }\end{array}$ & $\begin{array}{l}\text { Multiple } \\
\text { Analysis } \\
\text { Final Model } \\
\text { OR (CI 95\%) }\end{array}$ \\
\hline & & & $\left(\mathrm{N}=10^{\prime} 191\right)$ \\
\hline \multicolumn{4}{|l|}{ GP sex } \\
\hline Male & 6,693 & & \\
\hline Female & 5,324 & $1.06(0.94-1.22)$ & $1.05(0.90-1.22)$ \\
\hline \multicolumn{4}{|l|}{ GP age, y } \\
\hline$<35$ & 1,162 & & \\
\hline $35-44$ & 2,921 & $1.01(0.90-1.13)$ & $1.02(0.94-1.11)$ \\
\hline $45-54$ & 3,155 & $1.35(1.19-1.53)$ & $1.32(1.17-1.49)$ \\
\hline $55-64$ & 3,561 & $1.27(1.13-1.43)$ & $1.25(1.10-1.42)$ \\
\hline$\geq 65$ & 1,230 & $0.69(0.54-0.89)$ & $0.67(0.52-0.88)$ \\
\hline \multicolumn{4}{|l|}{ Rural/Urban area } \\
\hline Rural & 5,065 & & \\
\hline Urban & 6,898 & $1.08(0.98-1.18)$ & $1.12(1.03-1.22)$ \\
\hline \multicolumn{4}{|c|}{$\begin{array}{l}\text { Practice organizational \& } \\
\text { functional features }\end{array}$} \\
\hline \multicolumn{4}{|l|}{$\begin{array}{l}\text { Weekly workload } \\
\text { (hours/week) }\end{array}$} \\
\hline$\leq 40$ & 6,150 & & \\
\hline $41-50$ & 3,444 & $1.11(0.97-1.26)$ & $1.14(1.01-1.27)$ \\
\hline$>50$ & 2,315 & $1.26(1.09-1.47)$ & $1.26(1.12-1.42)$ \\
\hline \multicolumn{4}{|c|}{$\begin{array}{l}\text { Administrative task } \\
\text { ( } \% \text { total workload) }\end{array}$} \\
\hline$\leq 10$ & 4,044 & & \\
\hline $11-20$ & 3,957 & $1.10(0.97-1.25)$ & $1.14(1.01-1.29)$ \\
\hline$>20$ & 3,839 & $1.55(1.39-1.74)$ & $1.55(1.37-1.73)$ \\
\hline \multicolumn{4}{|c|}{ GP FTE in the practice } \\
\hline 1 & 2,351 & & \\
\hline 2 & 2,150 & $0.90(0.78-1.05)$ & $0.97(0.80-1.17)$ \\
\hline $3-5$ & 4,009 & $0.74(0.64-0.86)$ & $0.83(0.69-0.99)$ \\
\hline $6-10$ & 2,321 & $0.68(0.52-0.88)$ & $0.76(0.60-0.96)$ \\
\hline$>10$ & 804 & $0.77(0.55-1.06)$ & $0.82(0.62-1.08)$ \\
\hline \multicolumn{4}{|c|}{ Same-day appointment, \% } \\
\hline$>50$ & 7,704 & & \\
\hline About 50 & 1,607 & $1.20(0.98-1.47)$ & $1.15(0.96-1.37)$ \\
\hline $20-40$ & 1,275 & $1.51(1.31-1.74)$ & $1.49(1.29-1.71)$ \\
\hline$<20$ & 1,047 & $2.01(1.48-2.93)$ & $1.83(1.34-2.50)$ \\
\hline \multicolumn{4}{|l|}{ Home visits } \\
\hline No & 4,080 & & \\
\hline Yes & 7,824 & $1.23(1.11-1.36)$ & $0.89(0.83-0.96)$ \\
\hline \multicolumn{4}{|c|}{$\begin{array}{l}\text { Inter-visit contacts with } \\
\text { patients }\end{array}$} \\
\hline No & 1,493 & & \\
\hline Yes & 10,427 & $0.72(0.60-0.87)$ & $0.83(0.70-0.98)$ \\
\hline \multicolumn{4}{|c|}{$\begin{array}{l}\text { Information on clinical } \\
\text { targets }\end{array}$} \\
\hline No & 5,771 & & \\
\hline Yes & 6,118 & $0.73(0.59-0.91)$ & $0.80(0.66-0.98)$ \\
\hline \multicolumn{4}{|c|}{$\begin{array}{l}\text { Involved in coordinated } \\
\text { care with hospital }\end{array}$} \\
\hline No & 1,744 & & \\
\hline Yes & 10,139 & $0.71(0.63-0.80)$ & $0.84(0.76-0.93)$ \\
\hline
\end{tabular}


Table 3. Associations Between Work Dissatisfaction and Physician and Practice Characteristics, continued

\begin{tabular}{|c|c|c|c|}
\hline $\begin{array}{l}\text { Physician } \\
\text { Characteristics }\end{array}$ & No. & $\begin{array}{l}\text { Single } \\
\text { Independent } \\
\text { Variables } \\
\text { OR (CI 95\%) }\end{array}$ & $\begin{array}{l}\text { Multiple } \\
\text { Analysis } \\
\text { Final Model } \\
\text { OR (CI 95\%) }\end{array}$ \\
\hline \multicolumn{4}{|l|}{ Working with case manager } \\
\hline No & 2,914 & & \\
\hline Yes, external & 2,759 & $0.92(0.71-1.19)$ & $1.01(0.81-1.25)$ \\
\hline Yes, in practice & 6,261 & $0.74(0.62-0.90)$ & $0.84(0.75-0.95)$ \\
\hline \multicolumn{4}{|l|}{ Delay discharge } \\
\hline$\leq 2$ days & 3,757 & & \\
\hline 2 days-2 weeks & 6,473 & $1.30(1.15-1.47)$ & $1.23(1.07-1.41)$ \\
\hline 3-4 weeks & 960 & $1.92(1.64-2.25)$ & $1.66(1.39-1.98)$ \\
\hline$>1$ month or never & 558 & $2.00(1.79-2.23)$ & $1.82(1.52-2.19)$ \\
\hline \multicolumn{4}{|l|}{ Use of EHR } \\
\hline No & 1,621 & & \\
\hline Yes & 10,364 & $0.78(0.71-0.85)$ & $0.82(0.68-0.98)$ \\
\hline \multicolumn{4}{|l|}{$\begin{array}{l}\text { Electronic drug prescrip- } \\
\text { tion alerts }\end{array}$} \\
\hline No & 2,486 & & \\
\hline Yes, routinely & 8,049 & $0.89(0.73-1.07)$ & $1.11(0.89-1.38)$ \\
\hline Yes, occasionally & 1,343 & $1.19(0.99-1.44)$ & $1.43(1.17-1.75)$ \\
\hline Consultation duration & 11,934 & $0.99(0.97-1.01)$ & $\ldots$ \\
\hline $\begin{array}{l}\text { Information about hospital } \\
\text { admissions }\end{array}$ & & & $\ldots$ \\
\hline No & 7,441 & & \\
\hline Yes & 4,375 & $0.80(0.70-0.91)$ & \\
\hline Patient satisfaction surveys & & & $\ldots$ \\
\hline No & 6,046 & & \\
\hline Yes & 5,848 & $0.76(0.63-0.92)$ & \\
\hline Preventive targets to reach & & & $\ldots$ \\
\hline No & 8,056 & & \\
\hline Yes & 3,732 & $0.78(0.66-0.93)$ & \\
\hline Performance comparisons & & & $\ldots$ \\
\hline No & 5,742 & & \\
\hline Yes & 6,098 & $0.87(0.76-1.00)$ & \\
\hline $\begin{array}{l}\text { Coordinated care with } \\
\text { social workers }\end{array}$ & & & $\ldots$ \\
\hline No & 709 & & \\
\hline Occasionally & 5,218 & $0.77(0.67-0.90)$ & \\
\hline Routinely & 6,016 & $0.62(0.48-0.80)$ & \\
\hline $\begin{array}{l}\text { Contacts with home care } \\
\text { provider }\end{array}$ & & & $\ldots$ \\
\hline Never & 352 & & \\
\hline Occasionally & 5,710 & $0.79(0.62-1.00)$ & \\
\hline Routinely & 5,243 & $0.65(0.49-0.87)$ & \\
\hline $\begin{array}{l}\text { Information on changes } \\
\text { in patient health }\end{array}$ & & & $\ldots$ \\
\hline Never & 316 & & \\
\hline Occasionally & 4,903 & $0.79(0.62-0.99)$ & \\
\hline Routinely & 6,117 & $0.59(0.44-0.79)$ & \\
\hline Country variance & & & 0.35 \\
\hline \multicolumn{4}{|c|}{$\begin{array}{l}\mathrm{EHR}=\text { electronic health record; } \mathrm{FTE}=\text { full time equivalent; } \mathrm{GP}=\text { general practitioner; } \mathrm{OR}=\text { odds } \\
\text { ratio. }\end{array}$} \\
\hline \multicolumn{4}{|c|}{$\begin{array}{l}\text { Note: The final multivariate model was built in } 2 \text { steps: first, we retained from the univariate anal- } \\
\text { yses, the variables associated at a } P \text { value of } .2 \text { or less. Next, we performed a manual, backward, } \\
\text { stepwise selection (removal of the least significant variable at each step) to obtain a final model } \\
\text { (variables associated at a } P \text { value } \leq 05 \text { ). }\end{array}$} \\
\hline
\end{tabular}

perceived variables). Independent variables are sometimes correlated, which limits their simultaneous selection in the final model. Finally, as a cross-sectional study, causal conclusions could not be drawn. The study had several strengths, however, notably in terms of sample size and international comparisons, thanks to standardized methodology and questionnaire. To the best of our knowledge, it is the largest study performed in the domain of dissatisfaction at work among GPs.

\section{CONCLUSION}

This study contributes to the body of evidence demonstrating associations between GPs' job characteristics and organization and their satisfaction at work. However, the results also enable us think about room for improvement. Heavy workloads are clearly associated with work dissatisfaction. Instead of thinking about reducing GP's overall workloads, however, it might be more pertinent to foster new organizational methods. Group practices including other professionals, such as case managers, and the use of electronic health records seem to be good starting points. More administrative tasks could also be delegated. In addition, as some job stress models relate, occupational well-being often results from an imbalance between the great demands placed on professionals and the positive aspect of their jobs. Overloaded GPs could rebalance their workloads by diversifying their activities beyond clinical activities at the practice. Our results also suggested that improving the circulation of information and better coordinating care between primary care clinicians leads to greater job satisfaction. Primary care professionals could make efforts in these directions. Finally, regardless of our results, it would be useful if awareness of the occupational stress faced by GPs was raised during medical training. General practitioners should consider many of these issues themselves in order to improve their well-being at work wherever possible. Policy makers and professional bodies, however, should also consider these elements when recommending or implementing changes in structural practices. 
To read or post commentaries in response to this article, see it online at http://www.AnnFamMed.org/content/17/6/510.

Key words: job dissatisfaction; general practitioner; organizational factors

Submitted October 31, 2018; submitted, revised, April 13, 2019; accepted May 7, 2019.

Funding support: This analysis was funded entirely by the University of Lausanne's Institute of Family Medicine, Switzerland. CWF Health Policy Survey data were obtained for free from the Swiss Federal Office of Public Health.

Previous presentation: European Forum for Primary Care Annual Conference; September 24-25, 2018; Crete, Greece.

Supplemental Materials: Available at http://www.AnnFamMed. org/content/17/6/510/suppl/DC1/.

\section{References}

1. Eurofound. Fifth European Working Conditions Survey. Brussels, Belgium: Publications Office of the European Union; 2012.

2. Imo UO. Burnout and psychiatric morbidity among doctors in the UK: a systematic literature review of prevalence and associated factors. BJPsych Bulletin 2017;41(4):197-204

3. Shanafelt TD, Boone S, Tan L, et al. Burnout and satisfaction with work-life balance among US physicians relative to the general US population. Arch Intern Med. 2012;172(18):1377-1385.

4. Siegrist J, Shackelton R, Link C, et al. Work stress of primary care physicians in the US, UK and German health care systems. Social Sci Med. 2010;71(2):298-304.

5. Soler JK, Yaman H, Esteva M, et al; European General Practice Research Network Burnout Study Group. Burnout in European family doctors: the EGPRN study. Fam Pract. 2008;25(4):245-265..

6. Voltmer E, Rosta J, Siegrist J, Aasland OG. Job stress and job satisfaction of physicians in private practice: comparison of German and Norwegian physicians. Int Arch Occup Environ Health. 2012;85(7):819-828.

7. Spickard A Jr, Gabbe SG, Christensen JF. Mid-career burnout in generalist and specialist physicians. JAMA. 2002;288(12):1447-1450.

8. Behmann $M$, Schmiemann $G$, Lingner $H$, Kühne $F$, Hummers-Pradier E, Schneider N. Job satisfaction among primary care physicians: results of a survey. Dtsch Arztebl Int. 2012;109(11):193-200.

9. Ruotsalainen JH, Verbeek JH, Mariné A, Serra C. Preventing occupational stress in healthcare workers. Cochrane Database Syst Rev. 2015;(4):CD002892.

10. Gibson JS, Spooner M, Checkland S. K. Ninth National GP Worklife Survey. Manchester, England: Manchester Centre for Health Economics, University of Manchester; 2017.

11. Nørøxe KB, Pedersen AF, Bro F, Vedsted P. Mental well-being and job satisfaction among general practitioners: a nationwide crosssectional survey in Denmark. BMC Fam Pract. 2018;19(1):130.

12. Kirstine Andersen M, Pedersen LB, Waldorff FB. Retirement, job satisfaction and attitudes towards mandatory accreditation: a Danish survey study in general practice. BMJ Open. 2018;8(8):e020419.

13. Hirsch O, Adarkwah CC. The Issue of Burnout and Work Satisfaction in Younger GPs-A Cluster Analysis Utilizing the HaMEdSi Study. Int J Environ Res Public Health. 2018;15(10):E2190.

14. Barikani A, Javadi M, Mohammad A, Firooze B, Shahnazi M. Satisfaction and motivation of general physicians toward their career. Glob J Health Sci. 2012;5(1):166-173.
15. Bovier PA, Perneger TV. Predictors of work satisfaction among physicians. Eur J Public Health. 2003;13(4):299-305.

16. Calnan M, Wainwright D, Forsythe $M$, et al. Mental health and stress in the workplace: the case of general practice in the UK. Social Sci Med. 2001;52(4):499-507.

17. Scott A, Gravelle $H$, Simoens $S$, et al. Job satisfaction and quitting intentions: a structural model of British general practitioners. $\mathrm{Br}$ J Ind Relat. 2006;44(3):519-540.

18. Marchand C, Peckham S. Addressing the crisis of GP recruitment and retention: a systematic review. British J Gen Pract. 2017;67(657): e227-e37.

19. Gan Y, Gong Y, Chen Y, et al. Turnover intention and related factors among general practitioners in Hubei, China: a cross-sectional study. BMC Fam Pract. 2018;19(1):74.

20. Owen K, Hopkins T, Shortland T, Dale J. GP retention in the UK: a worsening crisis. Findings from a cross-sectional survey. BMJ Open. 2019;9(2):e026048.

21. Wright AA, Katz IT. Beyond burnout - redesigning care to restore meaning and sanity for physicians. N Engl J Med. 2018;378(4): 309-311.

22. van den Hombergh $P$, Künzi B, Elwyn $G$, et al. High workload and job stress are associated with lower practice performance in general practice: an observational study in 239 general practices in the Netherlands. BMC Health Serv Res. 2009;9:118.

23. Loerbroks A, Weigl M, Li J, Angerer P. Effort-reward imbalance and perceived quality of patient care: a cross-sectional study among physicians in Germany. BMC Public Health. 2016;16:342.

24. Linzer M, Manwell LB, Williams ES, et al. Working conditions in primary care: physician reactions and care quality. Ann Intern Med. 2009;151(1):28-36, w6-9.

25. Groenewegen PP, Hutten JB. Workload and job satisfaction among general practitioners: a review of the literature. Social Sci Med. 1991;32(10):1111-1119.

26. Van Ham I, Verhoeven AA, Groenier KH, Groothoff JW, De Haan J. Job satisfaction among general practitioners: a systematic literature review. Eur J Gen Pract. 2006;12(4):174-180.

27. Le Floch $B$, Bastiaens $H$, Le Reste JY, et al. Which positive factors determine the GP satisfaction in clinical practice? A systematic literature review. BMC Fam Pract. 2016;17(1):133.

28. Riisgaard H, Nexøe J, Le JV, Søndergaard J, Ledderer L. Relations between task delegation and job satisfaction in general practice: a systematic literature review. BMC Fam Pract. 2016;17(1):168.

29. Gregory ST, Menser T. Burnout among primary care physicians: a test of the areas of worklife model. J Healthc Manage. 2015;60(2): 133-148.

30. Sanchez-Piedra CA, Jaruseviciene L, Prado-Galbarro FJ, et al. Factors associated with professional satisfaction in primary care: results from EUprimecare project. Eur J Gen Pract. 2017;23(1):114-120.

31. Whalley D, Bojke C, Gravelle $H$, et al. GP job satisfaction in view of contract reform: a national survey. British J Gen Pract. 2006;56(523): 87-92.

32. Buciuniene I, Blazeviciene A, Bliudziute E. Health care reform and job satisfaction of primary health care physicians in Lithuania. BMC Fam Pract. 2005;6(1):10.

33. Peikes DN, Swankoski K, Hoag SD, et al. The effects of a primary care transformation initiative on primary care physician burnout and workplace experience. J Gen Intern Med. 2019;34(1):49-57.

34. Rao SK, Kimball AB, Lehrhoff SR, et al. The Impact of Administrative Burden on Academic Physicians: Results of a Hospital-Wide Physician Survey. Acad Med. 2017;92(2):237-43. doi:

35. Allen T, Whittaker W, Sutton M. Does the proportion of pay linked to performance affect the job satisfaction of general practitioners? Soc Sci Med. 2017;173(173):9-17. 
36. Ohlander J, Weigl M, Petru R, Angerer P, Radon K. Working conditions and effort-reward imbalance of German physicians in Sweden respective Germany: a comparative study. Int Arch Occup Environ Health. 2015;88(4):511-519.

37. Babbott S, Manwell LB, Brown R, et al. Electronic medical records and physician stress in primary care: results from the MEMO Study. J Am Med Inform Assoc. 2014;21(e1):e100-e106.

38. Rapoport R, Tipan L, Czyzewicz E. 2015 International Health Policy Survey of Primary Care Doctors: Methodology Report. New York, NY: Commonwealth Fund; 2015.

39. Osborn R, Moulds D, Schneider EC, Doty MM, Squires D, Sarnak DO. Primary care physicians in ten countries report challenges caring for patients with complex health needs. Health Aff (Millwood). 2015;34(12):2104-2112.

40. The Commonwealth Fund. 2015 International on Primary Care Doctors Topline. http://www.commonwealthfund.org/ /media/files/ surveys/2015/2015-ihp-survey_topline_11-20-15.pdf. Published Nov 20, 2015. Accessed May 29, 2018.
41. Woolhandler S, Himmelstein DU. Administrative work consumes one-sixth of U.S. physicians' working hours and lowers their career satisfaction. Int J Health Serv. 2014;44(4):635-642.

42. Thun S, Halsteinli V, Løvseth L. A study of unreasonable illegitimate tasks, administrative tasks, and sickness presenteeism amongst Norwegian physicians: an everyday struggle? BMC Health Serv Res. 2018;18(1):407.

43. Karasek R, Baker D, Marxer F, Ahlbom A, Theorell T. Job decision latitude, job demands, and cardiovascular disease: a prospective study of Swedish men. Am J Public Health. 1981;71(7):694-705.

44. Weidner AKH, Phillips RL Jr, Fang B, Peterson LE. Burnout and scope of practice in new family physicians. Ann Fam Med. 2018;16(3):200-205.

45. Bjertnaes OA, Iversen $\mathrm{HH}$, Bukholm G. International health policy survey in 11 countries: assessment of non-response bias in the Norwegian sample. BMC Health Serv Res. 2010;10:38.

\section{CHANGE-OF-ADDRESS FORM FAMILY MEDICINE}

Please complete this form and mail to the following address or fax to Annals Circulation at 913-906-6080:

Annals of Family Medicine, Circulation Department, 11400 Tomahawk Creek Pkwy, Leawood, KS 66211-2680

Check if member of sponsoring organization:

\section{$\sqsupset$ AAFP $\square$ ABFM $\square$ STFM $\square$ ADFM \\ $\square$ AFMRD $\square$ NAPCRG $\square$ CFPC}

ID number from label on your journal cover

OLD Information (Please print.)

Name

Company (if applicable)

Address (Street plus Apt or Ste)

City

Country

Postal Code (9-digit ZIP for US)

Telephone

Fax

E-Mail
NEW Information (Please print.)

\begin{tabular}{ll}
\hline Name \\
\hline Company (if applicable) & \\
\hline Address (Street plus Apt or Ste) & \\
\hline City & Postal Code (9-digit ZIP for US) \\
\hline Country & \\
\hline Telephone & \\
\hline E-Mail & \\
\hline
\end{tabular}

